Palavras chave:

Modelagem do crescimento e produção florestal Aproximação de funções Povoamentos não desbastados

Histórico: Recebido 12/03/201 I Aceito $31 / 08 / 2014$

Keywords: Modeling forest growth and yield Approximation of functions Unthinned stands

Correspondência: mayrabinoti@gmail.com
Mayra Luiza Marques da Silva Binoti', Helio Garcia Leite², Daniel Henrique Breda Binoti', José Marinaldo Gleriani²

\section{PROGNOSE EM NÍVEL DE POVOAMENTO DE CLONES DE EUCALIPTO EMPREGANDO REDES NEURAIS ARTIFICIAIS}

RESUMO: Objetivou-se, neste estudo, treinar, aplicar e avaliar a eficiência de redes neurais artificiais (RNA) para realizar a prognose da produção de povoamentos equiâneos de clones de eucalipto. Os dados utilizados foram provenientes de povoamentos localizados no sul da Bahia, totalizando cerca de 2.000 hectares de floresta. Foram utilizadas variáveis numéricas, como: idade, área basal, volume e variáveis categóricas, como classe de solo, textura, tipos de espaçamento, relevo, projeto e clone. Os dados foram divididos aleatoriamente em dois grupos: treinamento (80\%) e generalização (20\%). Foram treinadas redes de três tipos: perceptron, perceptron de múltiplas camadas e redes de função de base radial. As RNA que apresentaram os melhores desempenhos no treinamento e generalização foram selecionadas para realizar a prognose com dados, a partir do primeiro inventário florestal. Conclui-se que as RNA apresentaram resultados satisfatórios, comprovando o potencial e aplicabilidade da técnica na solução dos problemas de mensuração e manejo florestal.

\section{STAND-LEVEL PROGNOSIS OF EUCALYPTUS CLONES USING ARTIFICIAL NEURAL NETWORKS}

ABSTRACT: The objective of this study was to train, implement and evaluate the efficiency of artificial neural networks (ANN) to perform production prognosis of even-aged stands of eucalyptus clones. The data used were from plantations located in southern Bahia, totaling about 2,000 acres of forest. Numeric variables, such as age, basal area, volume and categorical variables, such as soil class texture, spacing, land relief, project and clone were used. The data were randomly divided into two groups: training $(80 \%)$ and generalization (20\%). Three types of networks were trained: perceptron, multilayer perceptron networks and radial basis function. The RNA that showed the best performance in training and generalization were selected to perform the prognosis with data from the first forest inventory. We conclude that the RNA had satisfactory results, showing the potential and applicability of the technique in solving measurement and forest management problems. 


\section{INTRODUÇÃO}

Em mensuração florestal, o termo prognose é utilizado como referência à predição, projeção ou qualquer outro procedimento que permita prever estoques de crescimento e, ou, de colheita em idades futuras. A predição envolve o uso de uma função que inclui a variável independente idade, enquanto que a projeção envolve funções onde a produção futura é relacionada com a produção atual, dentre outras variáveis. A prognose da produção é um dos três elementos essenciais do manejo sendo difícil estabelecer planos de manejo sem esse elemento (CAMPOS; LEITE, 2009). As funções são denominadas de modelos de crescimento e produção. Portanto, a modelagem do crescimento e produção consiste em construir, ajustar e aplicar as funções com o propósito de prognose para uso em diversas atividades florestais como a simulação da aplicação de tratamentos silviculturais.

A modelagem em nível de povoamento, também denominada povoamento total, não explica a variação do tamanho das árvores dentro do povoamento, pois estima a produção por unidade de área, com base em atributos do povoamento, como idade, área basal, índice de local, etc. (VANCLAY, 1994). O principal modelo empregado no Brasil é o de Clutter (CLUTTER, 1963). Nesse modelo, constituído por um sistema de equações de regressão, a produção é expressa em função das idades atual e futura, do índice de local na idade atual e das áreas basais atual e futura (CAMPOS; LEITE, 2009).

Uma alternativa à modelagem utilizando modelos de regressão é a utilização de redes neurais artificiais. Uma rede neural artificial (RNA) é um processador constituído de unidades de processamento simples (neurônios artificiais) que calculam determinadas funções. Essas unidades estão distribuídas em camadas e conectadas entre si por pesos que armazenam o conhecimento experimental e ponderam as entradas de cada unidade. O conhecimento adquirido torna-se disponível para uso (BRAGA et al., 2007).

As RNA têm apresentado desempenho superior aos modelos de regressão, em razão de diversos fatores como: estrutura maciça e, paralelamente, distribuída (camadas); habilidade de aprender e generalizar que as tornam capazes de resolver problemas complexos; são tolerantes a falhas e ruídos; podem modelar diversas variáveis e suas relações não-lineares; possibilidade de modelagem com variáveis categóricas (qualitativas), além das numéricas (quantitativas); analogia neurobiológica, pois as redes são inspiradas no cérebro humano (BULLINARIA, 20I0; HAYKIN, 200I; LEK et al., 1996).

A modelagem e prognose da produção florestal se enquadram na tarefa de aprendizagem de RNA denominada aproximação de funções. Essa tarefa consiste em treinar uma rede neural que aproxime a função desconhecida $f(x)$ que descreve o mapeamento dos pares de entrada-saída $\{(x|, y|)$, $(x 2, y 2), \ldots,(x n, y n)\}$ de um conjunto de $n$ exemplos de treinamento (HAYKIN, 200 I; JAIN et al., 1996). O treinamento, também denominado de aprendizagem, consiste no ajuste dos parâmetros da rede a partir de dados de treinamento (exemplos), a fim de desempenhar uma determinada tarefa (BRAGA et al., 2007; HAYKIN, 200I).

Para realizar a aproximação de funções, existem três tipos de RNA: Linear (Perceptron), Perceptrons de múltiplas camadas (MLP - Multilayer Perceptron) e Redes de funções de base radial (RBF - Radial Basis Function). Todos os tipos possuem uma camada de entrada que não realiza processamento, apenas recebe as variáveis de entrada e as direcionam à próxima camada e uma camada de saída, ou seja, fornece a resposta final da rede. Uma rede linear possui uma única camada de processamento, sendo, consequentemente, a camada de saída. Uma rede MLP pode ter uma ou mais camadas intermediárias (entre as camadas de entrada e de saída), em que seus neurônios, geralmente, possuem funções de ativação de base sigmoidais. Enquanto que uma RBF possui apenas uma camada intermediária com funções de ativação de base radiais, por exemplo, a função gaussiana (BRAGA et al., 2007; HAYKIN, 200I).

A utilização de redes neurais artificiais (RNA) tem se mostrado uma alternativa promissora em relação às técnicas de regressão para o manejo dos recursos florestais. Diversos trabalhos têm sido desenvolvidos visando à sua adaptação e parametrização para diversas situações como a estimação do volume de árvores (SILVA et al., 2009), crescimento e produção (BINOTI, 20I0), taper (DIAMANTOPOULOU, 2005; LEITE et al., 20II), modelos hipsométricos (BINOTI et al., $20 \mid 2 a$ ), modelagem da distribuição diamétrica (BINOTI et al., 20I2b) dentre outras aplicações. 
Neste estudo, objetivou-se modelar a produção volumétrica de povoamentos de clones de eucalipto em função de variáveis categóricas e numéricas e avaliar a exatidão da prognose empregando redes neurais artificiais.

\section{MATERIAL E MÉTODOS}

\section{Descrição dos dados}

Os dados utilizados foram provenientes de inventários florestais contínuos (IFC) conduzidos em povoamentos não desbastados de clones de eucalipto, localizados no sul da Bahia, em uma área de cerca de 2.000 hectares de floresta. As variáveis numéricas consideradas foram idade (meses), área basal $\left(\mathrm{m}^{2} \cdot \mathrm{ha}^{-1}\right)$ e volume $\left(\mathrm{m}^{3} \cdot \mathrm{ha}^{-1}\right)$ (Tabela I). Sendo o volume com casca para celulose até um diâmetro mínimo de $4 \mathrm{~cm}$. Enquanto que as variáveis categóricas foram projeto $(P)$, tipo de solo $(S)$, relevo $(R)$, textura $(T)$, clone $(C)$ e espaçamento $(E)$. O número de classes dessas variáveis categóricas foi $4,15,3,7,9$ e 6 , respectivamente. $O$ número de medições variou de 4 a 10 , compreendendo 276 parcelas permanentes, com área média de $214 \mathrm{~m}^{2}$.

TABELA 1 Análise descritiva das variáveis numéricas. TABLE 1 Descriptive analysis of numerical variables.

\begin{tabular}{cccccc}
\hline Variável & Mínimo & Máximo & Média & $\begin{array}{r}\text { Desvio } \\
\text { padrão }\end{array}$ & $\begin{array}{c}\text { Percentil } \\
90\end{array}$ \\
\hline $\begin{array}{c}\text { Área basal } \\
\left(\mathrm{m}^{2} \mathrm{ha}^{-1}\right)\end{array}$ & 1,1 & 48,8 & 20,6 & $\pm 5,9$ & 27,2 \\
$\begin{array}{c}\text { Idade } \\
(\text { meses })\end{array}$ & 21 & 137 & 71 & \pm 25 & 101 \\
$\begin{array}{c}\text { Volume } \\
\left(\mathrm{m}^{3} \mathrm{ha}^{-1}\right)\end{array}$ & 12,1 & 1111,7 & 435,5 & $\pm 189,6$ & 671,2 \\
\hline
\end{tabular}

Os dados, englobando todas as medições disponíveis, foram divididos, aleatoriamente, em dois conjuntos, um para o treinamento das redes (226 parcelas) e outro para avaliar a generalização das redes treinadas (50 parcelas), com uma proporção de cerca de $80 \%$ dos dados para treinamento e $20 \%$ para generalização.

Os pontos que extrapolaram a tendência geral de cada clone, em área basal ou volume em função da idade, não foram eliminados, a fím de verificar a capacidade das redes neurais artificiais em lidar com outliers ou ruídos.

\section{Treinamento das redes neurais artificiais}

O treinamento de uma RNA é o processo de ajuste de seus pesos, por meio de um algoritmo de aprendizagem, que extrai características dos dados fornecidos e tem por objetivo gerar uma rede que desempenhe a tarefa de interesse.

Os dados foram organizados em dois tipos de estrutura para modelagem: (A) informações dos inventários pareadas com amplitude de 12 meses, ou seja, IFCI-IFC2, IFC2-IFC3 e, assim, sucessivamente, ou seja, a estrutura dos dados para ajuste das RNA considera intervalos de um ano; (B) informações dos inventários pareados com diferentes intervalos de idade, ou seja, IFCI-IFC2, IFCI-IFC3,.., IFC2IFC3, IFC2-IFC4 e, assim, sucessivamente. Neste caso, realizou-se a combinação entre todos os IFCs disponíveis.

Foram treinadas redes para projetar o volume e também para projetar a área basal, pois a área basal futura foi considerada como entrada das redes para projetar o volume. Foram treinadas 600 redes para projetar área basal: 100 Lineares (Perceptron), 100 Perceptrons de Múltiplas Camadas (MLP) e 100 Redes de Função de Bases Radial (RBF) para cada estrutura; e 600 redes para projetar volume. Destas, foram préselecionadas 24 RNA (duas de cada tipo para cada estrutura para área basal e volume) com base na correlação entre observado e estimado.

A definição da arquitetura das redes, ou seja, número de neurônios por camada e número de camadas foi otimizada pela ferramenta Intelligent Problem Solver (IPS) do software Statistica 7 (STATSOFT, 2007). Diante do grande número de possíveis combinações das variáveis de entrada disponíveis foi solicitada a otimização dessa seleção pelo algoritmo BSO do IPS. O algoritmo utiliza do erro médio para a escolha da melhor arquitetura. As demais etapas do treinamento, como pré-processamento, o treinamento propriamente dito e o pós-processamento, também foram realizadas pelo IPS.

\section{Generalização das redes neurais artificiais}

A generalização é a capacidade de uma rede neural produzir saídas adequadas para entradas que não estavam presentes durante o treinamento 
(aprendizagem). Nessa etapa, foram utilizados dados de inventário de 50 parcelas permanentes não utilizados durante o treinamento. A aplicação das redes treinadas aos dados da generalização foi feita pelo software Statistica 7.

\section{Prognose da produção florestal}

A prognose consistiu na aplicação das redes que apresentaram melhor resultado, em termos de exatidão, no treinamento e na generalização. Os dados do primeiro inventário (primeira medição das parcelas permanentes) das 50 parcelas separadas para a generalização foram utilizados para projeção da área basal e do volume. Nessa etapa, também foi utilizado o software Statistica 7, para a aplicação das redes.

\section{Avaliação das estimativas geradas pelas redes neurais artificiais}

A avaliação das estimativas geradas pelas redes neurais, nas três etapas, treinamento, generalização e prognose, foi feita empregando estatísticas e análise gráfica de resíduos. As estatísticas empregadas foram a correlação entre os valores estimados e observados, de área basal e volume, e a raiz do erro quadrado médio (RMSE\%). A análise gráfica consistiu na inspeção estatística da dispersão dos erros (resíduos) percentuais em relação aos valores observados, sendo Y a saída observada nos inventários, Ŷ a saída estimada pela RNA (equação I).

erro $\%=\frac{(\hat{Y}-Y)}{Y} 100$

A correlação (2) entre os valores observados e estimados $\left(r_{\hat{y y y}}\right)$ indica a força e a direção da relação entre as duas variáveis. Embora não permita inferir, diretamente, sobre igualdade entre valores observados e estimados (CAMPOS e LEITE, 2009), a correlação indica o grau de associação entre valores observados e estimados e, juntamente com a análise de resíduos, permite inferir sobre a qualidade da prognose ou estimação. Quanto mais próxima de I, maior a correlação entre as variáveis, sendo $S^{2}$ a variância e cov a covariância.

$$
r_{\hat{Y}}=\frac{\operatorname{cov}(Y, \hat{Y})}{\sqrt{s^{2}(Y) s^{2}(\hat{Y})}}
$$

A raiz do erro quadrado médio (RMSE) avalia a diferença quadrática média entre os valores observados e os valores estimados (equação 3). Quanto menor o RMSE, melhor a precisão da estimativa (MEHTÄTALO et al., 2006), sendo $\bar{Y}$ a média da saída observada e $n$ é o número total de dados.

$\operatorname{RMSE}(\%)=\frac{100}{\bar{Y}} \sqrt{\frac{\sum_{i=1}^{n}\left(Y_{i}-\hat{Y}_{i}\right)^{2}}{n}}$

\section{RESULTADOS E DISCUSSÃO}

\section{Projeção da área basal}

Nas 12 redes pré-selecionadas para projetar a área basal, em geral, todas as variáveis de entradas disponíveis, categóricas e numéricas, foram importantes e selecionadas pelo algoritmo de otimização (Tabela 2).

A avaliação estatística das estimativas das redes, no treinamento e na generalização, mostrou que tanto pela correlação quanto pelo RMSE\%, as redes da estrutura $A$ ( $\mathrm{I}$ a 6 ) foram mais precisas do que as redes da estrutura $B$ ( 7 a I2), com maior correlação e menor RMSE\% (Tabela 2). A estrutura $A$ foi superior à $B$, pelo fato de projetar a área basal com amplitude de idade menor e constante, ou seja, da atual para o próximo ano, enquanto que a estrutura $B$ projeta a área basal com amplitudes de idade maiores e variáveis, pois projeta a área basal atual para os próximos nove anos.

Das redes da estrutura $A$, as redes 5 e 6 apresentaram melhor treino (maior correlação e menor RMSE\%), porém pior generalização (maior RMSE\%). Não é suficiente uma rede apenas bem treinada, pois uma boa generalização é essencial para a aplicação da mesma a novos dados. Assim, as redes 5 e 6 (duas $\mathrm{RBF}$ ), foram desconsideradas para projetação da área basal. Uma possível causa deste desempenho pode ser a ocorrência do sobretreinamento, ou seja, a rede memoriza os dados de treinamento, suas características 
TABELA 2 Características e precisão das redes neurais artificiais selecionadas pra projetar a área basal.

TABLE 2 Characteristics and accuracy of selected artificial neural networks to project the basal area.

\begin{tabular}{|c|c|c|c|c|c|c|c|c|c|c|}
\hline \multirow{2}{*}{ RNA } & \multirow{2}{*}{ Tipo* } & \multirow{2}{*}{ Arquitetura** } & \multirow{2}{*}{$\begin{array}{l}\text { Entradas } \\
\text { numéricas }\end{array}$} & \multirow{2}{*}{$\begin{array}{c}\text { Entradas } \\
\text { categóricas }\end{array}$} & \multicolumn{2}{|c|}{ Treinamento } & \multicolumn{2}{|c|}{ Generalização } & \multicolumn{2}{|c|}{ Prognose } \\
\hline & & & & & $r_{Y \hat{Y}}$ & RMSE $\%$ & $r_{Y \hat{Y}}$ & RMSE \% & $r_{Y \hat{Y}}$ & RMSE\% \\
\hline 1 & Linear & $38-1$ & $I_{1}, I_{2}, B_{1}$ & $\mathrm{P}, \mathrm{S}, \mathrm{R}, \mathrm{T}, \mathrm{E}$ & 0,9842 & 5,20 & 0,9825 & 4,92 & 0,9825 & 4,92 \\
\hline 2 & Linear & $47-1$ & $I_{1}, I_{2}, B_{1}$ & $\mathrm{P}, \mathrm{S}, \mathrm{R}, \mathrm{T}, \mathrm{C}, \mathrm{E}$ & 0,9852 & 5,02 & 0,9820 & 4,97 & 0,9820 & 4,97 \\
\hline 3 & MLP & $20-1-1$ & $\mathrm{I}_{1}, \mathrm{~B}_{1}$ & $\mathrm{R}, \mathrm{C}, \mathrm{E}$ & 0,9842 & 5,16 & 0,9835 & 4,78 & 0,9835 & 4,78 \\
\hline 4 & MLP & 12-2-1 & $\mathrm{I}_{2}, \mathrm{~B}_{1}$ & $P, E$ & 0,9843 & 5,15 & 0,9828 & 4,85 & 0,9828 & 4,85 \\
\hline 5 & RBF & $41-197-1$ & $\mathrm{I}_{1}, \mathrm{I}_{2}, \mathrm{~B}_{1}$ & $\mathrm{P}, \mathrm{S}, \mathrm{R}, \mathrm{T}, \mathrm{C}, \mathrm{E}$ & 0,9874 & 4,62 & 0,9734 & 6,08 & - & - \\
\hline 6 & $\mathrm{RBF}$ & $41-131-1$ & $I_{1}, I_{2}, B_{1}$ & $\mathrm{P}, \mathrm{S}, \mathrm{R}, \mathrm{T}, \mathrm{C}, \mathrm{E}$ & 0,9872 & 4,66 & 0,9800 & 5,24 & - & - \\
\hline 7 & Linear & $38-1$ & $I_{1}, I_{2}, B_{1}$ & P, S, R, T, E & 0,8939 & 10,52 & 0,9540 & 9,88 & - & - \\
\hline 8 & Linear & $47-1$ & $I_{1}, I_{2}, B_{1}$ & $\mathrm{P}, \mathrm{S}, \mathrm{R}, \mathrm{T}, \mathrm{C}, \mathrm{E}$ & 0,9112 & 9,54 & 0,9559 & 8,90 & - & - \\
\hline 9 & MLP & $34-3-1$ & $I_{1}, I_{2}, B_{1}$ & S, T, C & 0,9208 & 9,03 & 0,9357 & 9,83 & - & - \\
\hline 10 & MLP & $32-2-1$ & $\mathrm{I}_{1}, \mathrm{I}_{2}, \mathrm{~B}_{1}$ & $\mathrm{P}, \mathrm{R}, \mathrm{T}, \mathrm{C}, \mathrm{E}$ & 0,9258 & 8,76 & 0,9519 & 8,88 & - & - \\
\hline 11 & RBF & $44-383-1$ & $\mathrm{I}_{1}, \mathrm{I}_{2}, \mathrm{~B}_{1}$ & $\mathrm{P}, \mathrm{S}, \mathrm{T}, \mathrm{C}, \mathrm{E}$ & 0,9583 & 6,63 & 0,9170 & 10,56 & - & - \\
\hline 12 & RBF & $44-380-1$ & $\mathrm{I}_{1}, \mathrm{I}_{2}, \mathrm{~B}_{1}$ & $\mathrm{P}, \mathrm{S}, \mathrm{T}, \mathrm{C}, \mathrm{E}$ & 0,9590 & 6,58 & 0,9478 & 8,59 & - & - \\
\hline
\end{tabular}

* Tipo de RNA: Linear $=$ Perceptron, MLP $=$ Multilayer Perceptron, RBF $=$ Radial Basis Function. ** Número de neurônios em cada camada. $\mathrm{I}_{1}=$ idade atual, $\mathrm{I}_{2}=$ idade futura, $\mathrm{B}_{1}=$ área basal atual, $\mathrm{P}=$ projeto, $\mathrm{S}=$ tipo de solo, $\mathrm{R}=$ relevo, $\mathrm{T}=$ textura, $\mathrm{C}=$ clone, $\mathrm{E}=$ espaçamento.

e ruídos, o que faz com que a função estimada "passe" pela maioria dos pontos de treinamento, gerando um "bom" treino. Entretanto, isso gera uma piora na capacidade de generalização da rede (BRAGA et al., 2007). Segundo Bullinaria (2009), existem várias técnicas para evitar esse problema, como parar o treinamento mais cedo (menos ciclos, interações e etc.) e adicionar ruídos aos padrões de treinamento, porém não foi objetivo deste estudo avaliá-las.

As demais redes da estrutura $A$, de 1 a 4 , tiveram valores similares de correlação e RMSE\% para o treino e generalização, porém a rede 3 mostrou-se superior às demais. Assim, a rede 3 foi utilizada para projetar a área basal, utilizada como entrada das redes para projetar o volume.

\section{Projeção do volume}

Nas 12 redes pré-selecionadas para projetar o volume, todas as variáveis de entradas disponíveis, categóricas e numéricas, foram importantes e selecionadas pelo algoritmo de otimização (Tabela 3). Dentre as variáveis categóricas, clone (C) foi predominante, sendo selecionada em todas as redes. Uma possível justificativa é que para estimar a produção volumétrica, o clone, em razão da sua especificidade, representa as demais características ambientais, como tipo de solo, relevo, textura e prescrições como espaçamento. Dentre as variáveis numéricas, o volume inicial (VI) e a área basal futura (B2) foram as variáveis predominantes, pela sua alta correlação com a produção volumétrica futura (V2), 0,98 e 0,84 , respectivamente.

As redes treinadas a partir da estrutura $B$ (19 a 24) forneceram generalizações inferiores às da estrutura $\mathrm{A}$ ( 13 a 18 ), com maiores valores de RMSE\%. $\mathrm{Na}$ estrutura $A$, as redes apresentaram estimativas com precisão semelhante, tanto em correlação quanto em RMSE\%, no treinamento e na generalização (Tabela 3).

$\mathrm{Na}$ prognose da produção florestal, os dados do primeiro inventário florestal contínuo (IFC), juntamente com a área basal projetada pela RNA 3, foram utilizados pra projetar 0 volume. A rede 18 (RBF) foi superior às demais na prognose da produção, o que pode ser verificado pelo menor valor de RMSE\% e maior correlação.

A prognose da produção volumétrica realizada pela rede 18 conseguiu modelar a tendência de crescimento de cada um dos oito clones presentes nas 50 parcelas permanentes selecionadas para a generalização (Figura I). Apesar de considerar todos os clones, como classes da variável categórica, a rede 
TABELA 3 Características e precisão das redes neurais artificiais selecionadas pra projetar o volume.

TABLE 3 Characteristics and accuracy of selected artificial neural networks to project the volume.

\begin{tabular}{|c|c|c|c|c|c|c|c|c|c|c|}
\hline \multirow{2}{*}{ RNA } & \multirow{2}{*}{ Tipo* } & \multirow{2}{*}{ Arquitetura** } & \multirow{2}{*}{$\begin{array}{l}\text { Entradas } \\
\text { numéricas }\end{array}$} & \multirow{2}{*}{$\begin{array}{c}\text { Entradas } \\
\text { categóricas }\end{array}$} & \multicolumn{2}{|c|}{ Treinamento } & \multicolumn{2}{|c|}{ Generalização } & \multicolumn{2}{|c|}{ Prognose } \\
\hline & & & & & $r_{Y \hat{Y}}$ & RMSE $\%$ & $r_{Y \hat{Y}}$ & RMSE \% & $r_{Y \hat{Y}}$ & RMSE\% \\
\hline 13 & Linear & $49-1$ & $\mathrm{I}_{1}, \mathrm{I}_{2}, \mathrm{~B}_{1}, \mathrm{~V}_{1}, \mathrm{~B}_{2}$ & $\mathrm{P}, \mathrm{S}, \mathrm{R}, \mathrm{T}, \mathrm{C}, \mathrm{E}$ & 0,9946 & 4,58 & 0,9942 & 4,48 & 0,9560 & 12,35 \\
\hline 14 & Linear & $48-1$ & $\mathrm{I}_{1}, \mathrm{~B}_{1}, \mathrm{~V}_{1}, \mathrm{~B}_{2}$ & $\mathrm{P}, \mathrm{S}, \mathrm{R}, \mathrm{T}, \mathrm{C}, \mathrm{E}$ & 0,9948 & 4,49 & 0,9944 & 4,44 & 0,9628 & 11,49 \\
\hline 15 & MLP & $12-2-1$ & $\mathrm{~B}_{1}, \mathrm{~V}_{1}, \mathrm{~B}_{2}$ & C & 0,9948 & 4,47 & 0,9946 & 4,34 & 0,9615 & 11,60 \\
\hline 16 & MLP & $13-2-1$ & $\mathrm{I}_{1}, \mathrm{~B}_{1}, \mathrm{~V}_{1}, \mathrm{~B}_{2}$ & C & 0,9950 & 4,40 & 0,9950 & 4,16 & 0,9305 & 15,49 \\
\hline 17 & RBF & $11-133-1$ & $\mathrm{~V}_{1}, \mathrm{~B}_{2}$ & C & 0,9941 & 4,79 & 0,9918 & 5,40 & 0,9609 & 11,54 \\
\hline 18 & $\mathrm{RBF}$ & $26-133-1$ & $\mathrm{~V}_{1}, \mathrm{~B}_{2}$ & S, C & 0,9932 & 5,11 & 0,9923 & 5,14 & 0,9652 & 10,89 \\
\hline 19 & Linear & 48-1 & $\mathrm{I}_{2}, \mathrm{~B}_{1}, \mathrm{~V}_{1}, \mathrm{~B}_{2}$ & $P, S, R, T, C, E$ & 0,9847 & 6,37 & 0,9862 & 7,66 & - & - \\
\hline 20 & Linear & $49-1$ & $I_{1}, I_{2}, B_{1}, V_{1}, B_{2}$ & $P, S, R, T, C, E$ & 0,9849 & 6,31 & 0,9865 & 7,43 & - & - \\
\hline 21 & MLP & $26-3-1$ & $\mathrm{I}_{2}, \mathrm{~B}_{2}$ & S, C & 0,9910 & 4,88 & 0,9872 & 6,63 & - & - \\
\hline 22 & MLP & 44-3-1 & $I_{1}, I_{2}, V_{1}, B_{2}$ & $\mathrm{~S}, \mathrm{R}, \mathrm{T}, \mathrm{C}, \mathrm{E}$ & 0,9915 & 4,74 & 0,9887 & 6,39 & - & - \\
\hline 23 & RBF & $43-966-1$ & $I_{1}, I_{2}, B_{1}, V_{1}, B_{2}$ & $\mathrm{P}, \mathrm{S}, \mathrm{R}, \mathrm{T}, \mathrm{C}$ & 0,9931 & 4,29 & 0,9637 & 11,71 & - & - \\
\hline 24 & RBF & $43-738-1$ & $\mathrm{I}_{1}, \mathrm{I}_{2}, \mathrm{~B}_{1}, \mathrm{~V}_{1}, \mathrm{~B}_{2}$ & $\mathrm{P}, \mathrm{S}, \mathrm{R}, \mathrm{T}, \mathrm{C}$ & 0,9928 & 4,38 & 0,9787 & 8,62 & - & - \\
\hline
\end{tabular}

* Tipo de RNA: Linear = Perceptron, MLP = Multilayer Perceptron, RBF = Radial Basis Function. ** Número de neurônios em cada camada. II = idade atual, $\mathrm{I} 2$ = idade futura, $\mathrm{BI}=$ área basal atual, $\mathrm{B} 2$ = área basal futura, $\mathrm{P}=$ projeto, $\mathrm{S}=$ tipo de solo, $\mathrm{R}$ $=$ relevo, $\mathrm{T}=$ textura, $\mathrm{C}=$ clone, $\mathrm{E}=$ espaçamento.

Clone 1

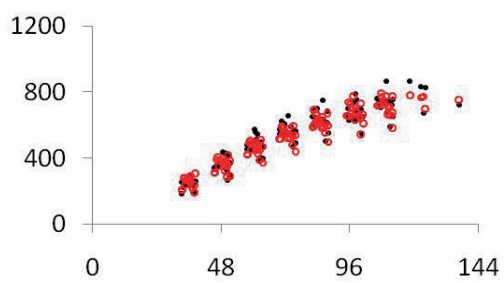

Clone 4

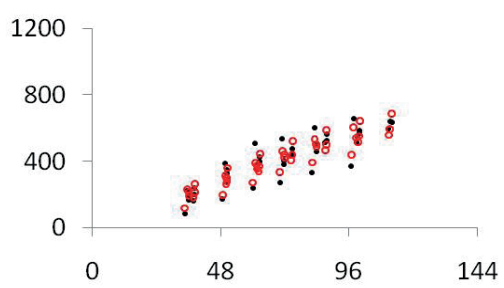

Clone 2

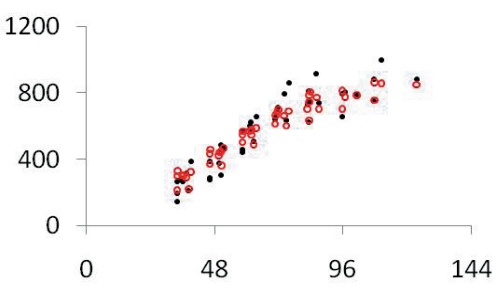

Clone 5

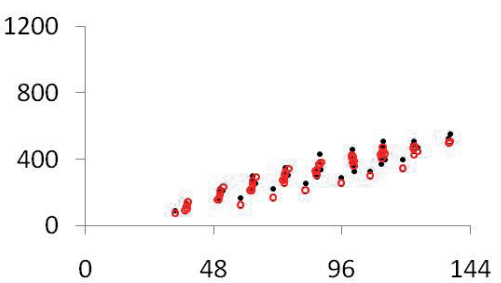

Clone 3

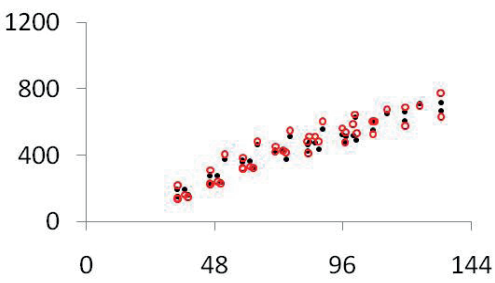

Clone 6

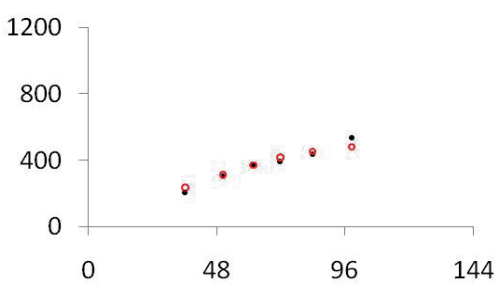

Clone 7
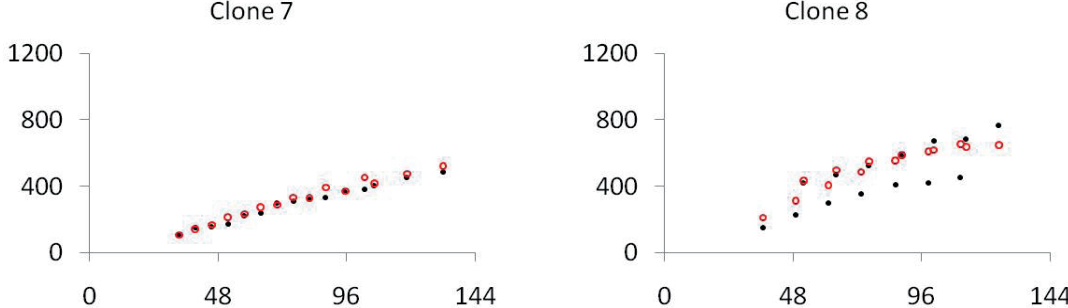

FIGURA 1 Projeção da produção volumétrica, em $\mathrm{m}^{3}$ ha-1 (eixo y) a partir de informações do primeiro inventário $\left({ }^{\circ}\right)$, em função da idade em meses (eixo $\mathrm{x}$ ), comparada com os dados observados $(\bullet)$.

FIGURE 1 Projected production, in $\mathrm{m}^{3}$ ha-1 (y axis) from information of first inventory $\left(^{\circ}\right)$, depending on age in months ( $\mathrm{x}$ axis) compared with observed data $(\cdot)$. 
possui um conjunto único de parâmetros para projetar o volume para todos os clones, ou seja, uma rede para modelar os oito clones, ao invés de uma rede para cada clone, mostrando uma grande vantagem operacional em relação aos clássicos modelos de crescimento e produção.

Uma desvantagem observada nas redes neurais obtidas pela estrutura $A$ foi a perda de precisão quando o intervalo de idades para projeção é maior que 12 meses, pois, essa amplitude foi utilizada no treinamento das redes. Para aplicar as redes da estrutura A, por exemplo, para obter os volumes de 2010 e 201 I, a partir do IFC de 2009, deve-se projetar as informações de 2009 para 2010, os valores obtidos servem de entrada da RNA para a projeção de 2010 para 20 I I. Assim, não é possível projetar para períodos maiores que 12 meses e garantir uma boa precisão das estimativas pelas redes obtidas pela estrutura $A$.

Conforme os histogramas de frequência percentuais dos erros percentuais das estimativas das RNA (Figura 2 e 3), a maioria dos erros concentrouse em $\pm 7,5 \%$, no treinamento e na generalização e em $\pm 12,5 \%$ na prognose. Considerando que essas estatísticas são em nível de parcela permanente, pode-se inferir que os resultados da prognose com RNA foram altamente satisfatórios.
Treinamento
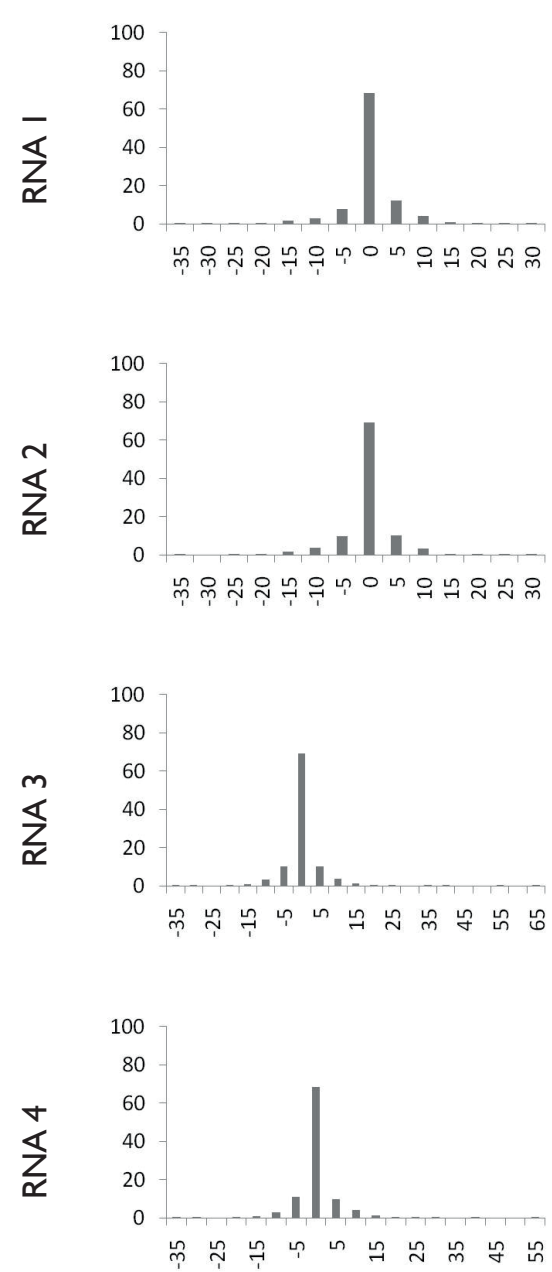

Generalização
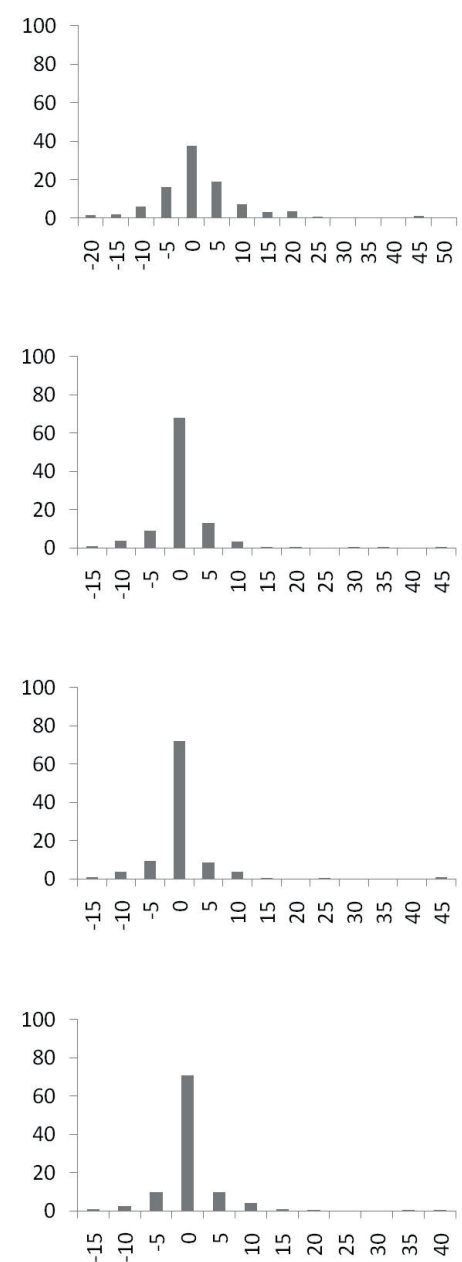

Prognose
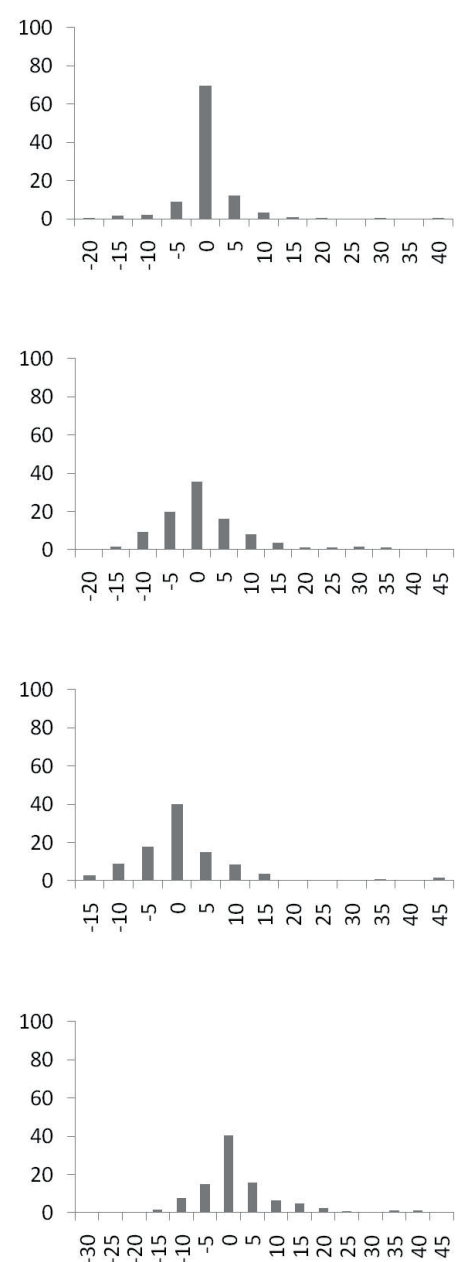

FIGURA 2 Frequência percentual (eixo y) dos erros percentuais (eixo x) das estimativas das RNA para projeção da área basal, no treinamento, generalização e prognose das redes de 1 a 4 , respectivamente.

FIGURE 2 Percentage frequency (y axis) of percentage errors (x axis) of the estimates of RNA to the basal area projection, in training, generalization and prognosis of networks 1-4, respectively. 
Treinamento
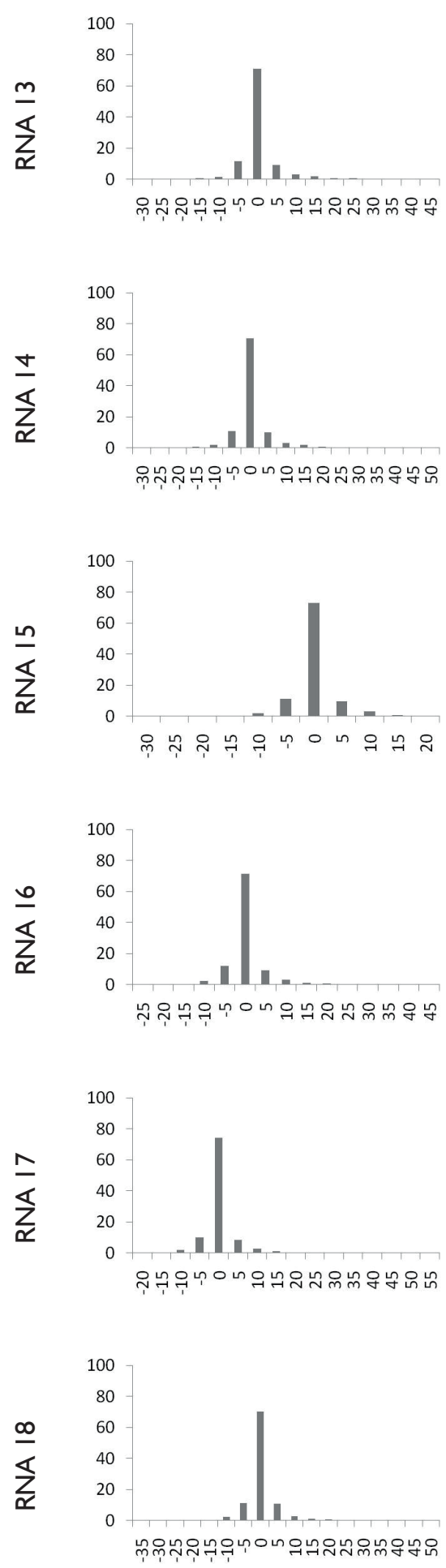

\section{Generalização}
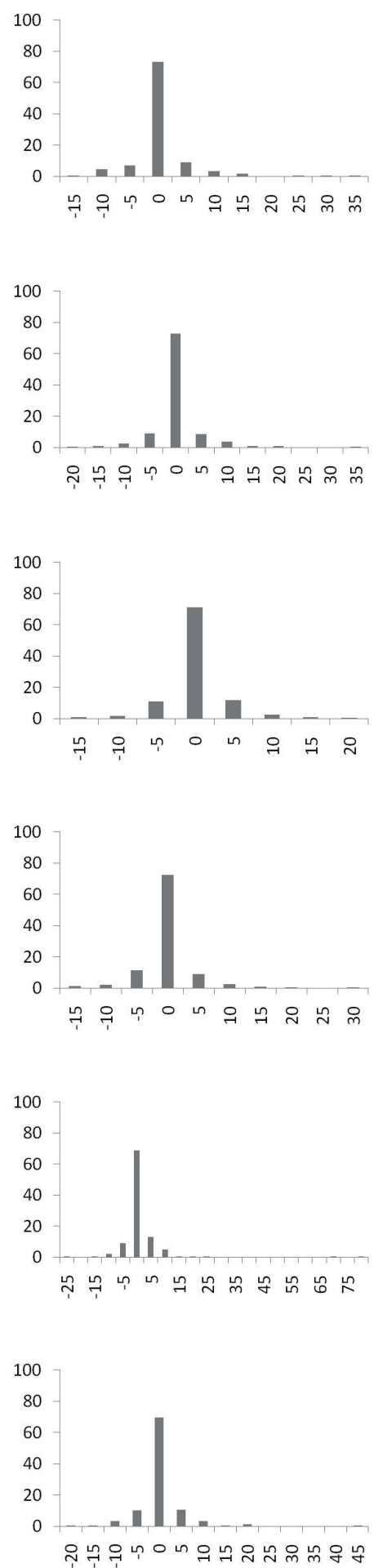

Prognose
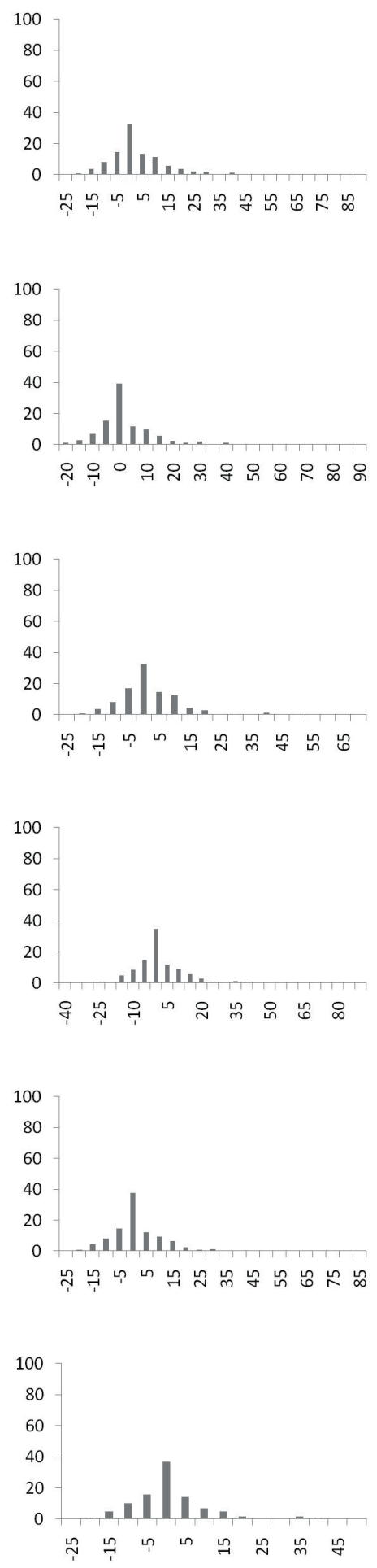

FIGURA 3 Frequência percentual (eixo y) dos erros percentuais (eixo $\mathrm{x}$ ) das estimativas das RNA para projeção do volume, no treinamento, generalização e prognose das redes de 13 a 18, respectivamente.

FIGURE 3 Percentage frequency (y axis) of percentage errors (x axis) of the estimates of RNA to the volume projection, in training, generalization and prognosis of networks 13-18, respectively. 


\section{CONCLUSÕES}

Tanto na projeção da área basal quanto na projeção do volume, observou-se que as redes neurais artificiais obtidas a partir da estrutura $A$, onde informações dos inventários foram pareadas com amplitude de 12 meses, são mais precisas que as redes obtidas da estrutura (B), onde as informações dos inventários foram pareadas com diferentes amplitudes.

Em geral, todas as variáveis, categóricas e numéricas, utilizadas como entradas das redes foram importantes. Sendo predominante, as variáveis clone, volume inicial e área basal futura, na projeção da produção volumétrica.

Redes neurais artificiais dos tipos Linear, MLP e RBF são capazes de desempenhar a tarefa de aproximação de funções para a projeção da área basal e do volume em povoamentos de clones de eucalipto.

Redes neurais artificiais são capazes de realizar a prognose da produção volumétrica em nível de povoamento, comprovando o grande potencial da técnica para aplicações na área de mensuração e manejo florestal.

\section{REFERÊNCIAS}

BINOTI, D. H. B.; BINOTI, M. L. M. da S.; LEITE, H. G.; SILVA, A. Redução dos custos em inventário de povoamentos equiâneos utilizando redes neurais artificiais. Agrária, Recife, v. 8, p. 125-129, 2012a.

BINOTI, D. H. B.; BINOTI, M. L. M. da S.; LEITE, H. G.; SILVA, A.; SANTOS, A. C. A. Modelagem da distribuição diamétrica em povoamentos de eucalipto submetidos a desbaste utilizando autômatos celulares. Revista Árvore, Viçosa, v. 35, p. I25-136, 2012b.

BINOTI, M. L. M. da S. Redes neurais artificiais para prognose da produção de povoamentos não desbastados de eucalipto. 2010. 54 f. Dissertação (Mestrado em Ciência Florestal) - Universidade Federal de Viçosa, Viçosa, 2010.
BRAGA, A. P.; CARVALHO, A. P. L. F.; LUDEMIR, T. B. Redes neurais artificiais: teoria e aplicações. 2. ed. Rio de Janeiro: LTC, 2007. 226 p.

BULLINARIA, J. A. Introduction to neural computation: notas de aula. Disponível em: <http://www.cs.bham. ac.uk/ jxb/inc.html>. Acesso em: 10 dez. 2010.

CAMPOS, J. C. C.; LEITE, H. G. Mensuração florestal: perguntas e respostas. 3. ed. Viçosa, MG: UFV, 2009. 548 p.

CLUTTER, J. L. Compatible growth and yield for loblolly pine. Forest Science, Cambridge, v. 9, n. 3, p. 354-37I, 1963.

DIAMANTOPOULOU, M. J. Artificial neural networks as an alternative tool in pine bark volume estimation. Computers and Electronics in Agriculture, Philadelphia, v. 10, p. 235-244, 2005

HAYKIN, S. Redes neurais: princípios e prática. 2. ed. Porto Alegre: Bookman, 200I. 900 p.

JAIN, A. K.; MAO, J.; MOHIUDDIN, K. M. Artificial neural networks: a tutorial. Computer, Oxford, v. 29, n. 3, p. 31 44, 1996.

LEITE, H. G.; SILVA, M. L. M.; BINOTI, D. H. B.; FARDIN, L.; TAKIZAWA, F. H. Estimation of inside-bark diameter and heartwood diameter for Tectona grandis Linn. trees using artificial neural networks. European Journal of Forest Research, Berlin, v. I30, n. 2, p. 263-269, 201 I.

LEK, S.; DELACOSTE, M.; BARAN, P.; DIMOPOULOS, I.; LAUGA, J.; AULAGNIER, S. Application of neural networks to modelling nonlinear relationships in ecology. Ecological Modelling, Philadelphia, v. 90, p. 39-52, 1996.

MEHTÄTALO, L.; MALTAMO, M.; KANGAS, A. The use of quantile trees in the prediction of the diameter distribution of a stand. Silva Fennica, Vantaa, v. 40, n. 3, p. 50I-5I6, 2006.

STATSOFT. Statistica: data analysis software system. Version 7. 2007. Disponível em: <http://www.statsoft.com>. Acesso em: 10 dez. $201 \mathrm{l}$.

VANCLAY, J. K. Modelling forest growth and yield. Wallingford: CAB International, 1994. 312 p. 